\title{
Disadvantaged neighborhoods, birth weight, and problem behavior in five- and six-year-old pre-school children: Evidence from a cohort born in Amsterdam
}

\author{
Unnati Rani Saha $^{\text {a,d, }}$, Govert E. Bijwaard ${ }^{b}$, Nazeem Muhajarine ${ }^{c}$, Tanja GM. Vrijkotte ${ }^{\mathrm{d}}$ \\ a Department of Public Health, Erasmus MC, University Medical Center Rotterdam, Rotterdam, the Netherlands \\ ${ }^{\mathrm{b}}$ Netherlands Interdisciplinary Demographic Institute, NIDI-KNAW/University of Groningen, Groningen, the Netherlands \\ ${ }^{\mathrm{c}}$ Community Health and Epidemiology, Director, Saskatchewan Population Health and Evaluation Research Unit, University of Saskatchewan, Saskatchewan, Canada \\ ${ }^{\mathrm{d}}$ Department of Public Health, Amsterdam Public Health Research Institute, Amsterdam UMC, University of Amsterdam, Amsterdam, the Netherlands
}

\section{A R T I C L E I N F O}

\section{Keywords:}

Neighborhood environment

Child health

Birth weight

Problem behavior

Amsterdam

\begin{abstract}
A B S T R A C T
Rationale: Low birth weight has been found to increase the problem behavior of children. Yet, little attention has been given to adequately account for the impact of the child's neighborhood on this relation. The residential neighborhood is a choice, based on factors that are usually not observed that may also influence birth weight and problem behavior.

Objective: Using a model that accounts for such endogeneity of both neighborhood choice and birth weight, we have analyzed behavioral problems in 4210 pre-school children between the ages of 5 and 6 , birth weight, and neighborhood status, simultaneously.

Method: The data used are from the Amsterdam Born Children and their Development (ABCD) cohort for whom a complete prospective record of birth outcomes, pregnancy, socio-demographic characteristics, and indicators of problem behavior are available. Neighborhood data obtained from Statistics Netherlands are merged with the ABCD data file.

Results: Our results suggest that ignoring endogeneity attenuates the effect of disadvantaged neighborhoods on both birth weight and problem behavior in pre-school children. Living in a disadvantaged neighborhood decreases the birth weight and increases the probability of problem behavior. Accounting for the endogeneity of neighborhood choice increases the estimated impacts (marginal effects: from $-10 \%$ to $-44 \%$ for birth weight and from $3 \%$ to $11 \%$ for problem behavior). Lower birth weight increases the probability of problem behavior, but it is only significant after adjusting for endogeneity. The coefficients of other factors have the expected associations with problem behavior.

Conclusions: These significant effects of disadvantaged neighborhood on birth weight and problem behavior could inform policies and practices that improve neighborhood development for children born in Amsterdam.
\end{abstract}

\section{Introduction}

Evidence continues to grow suggesting that preterm and low birth weight infants are at increased risk of developing behavior disorders/ problem behavior, emotional symptoms, conduct problems, hyperactivity/inattention problems, and peer relationship problems when they reach school age (Fan et al., 2013; Hille et al., 2001; Hornman et al., 2016; Jackson and Beaver, 2015; Kelly et al., 2001; Wiles et al., 2006). Jackson and Beaver (2015) indicated that low birth weight is an important risk factor for the development of Attention-Deficit
Hyperactivity Disorder (ADHD) during childhood. A large number of studies have suggested that the effect of birth weight on problem behavior is highly influenced by the child's environment, at home or in the wider context (see Kelly et al., 2001; Laucht et al., 2001; Shah et al., 2013; Tully et al., 2004). These studies revealed that birth outcome and social environment exert independent and potentially interactive effects on behavior in children. Yet, how a child's neighborhood context affects birth weight and how, in turn, it affects problem behavior, both directly and indirectly, has been largely ignored in the literature.

Neighborhood disadvantage may also be linked to low birth weight

\footnotetext{
* Corresponding author. P.O. Box 2040, 3000, CA, Rotterdam, the Netherlands.

E-mail address: u.saha@erasmusmc.nl (U.R. Saha).
} 
due to its impact on maternal health during pregnancy-for example, maternal stress. Gavin et al. (2012) demonstrated that maternal social disadvantage is associated with poorer health status in pregnancy, which, in turn, adversely affects birth outcomes. Maternal health during pregnancy and delivery (e.g., obesity, gestational hypertension, prenatal stress and the accumulation of these, and other, maternal medical risks) has important implications for the behavior of their offspring, including exhibiting problem behavior (Jackson and Vaughn, 2018; Robinson et al., 2009). Thus, if maternal health is affected by the neighborhood context, accounting for this factor is very relevant in the analysis of birth weight on exhibiting problem behavior.

Further, there are several other factors that raise the issue of endogeneity, such as genetic factors and/or maternal/familial behaviors and investments that influence both birth weight and problem behavior. Furthermore, Shum et al. (2008) stressed that ignoring important key variables (e.g., shared environments) may confound the birth weight and problem behavior relationship. Unfortunately, we do not observe these factors in our data, but our model implicitly accounts for them. Despite increased attention to conditional effects (the impact of birth weight conditional on parental or environmental situation), few studies adequately control for shared environmental influences (Jackson and Beaver, 2015). Thus, it remains a challenge, due to confounding factors inherent in neighborhood research, to account for the impact of the neighborhood context in the relation between birth weight and problem behavior, and how the neighborhood context shapes this relationship. This study aims to address this issue.

Leventhal and Brooks-Gunn (2000) suggest that researchers control for three essential confounding factors in neighborhood analysis. First, the simultaneity problem, such as interactions between children and families, which are bidirectional in nature (see Sameroff and Chandler, 1975), and those between families and neighborhood as well (see Leventhal and Brooks-Gunn, 2000). Second, the problem of omitted context variables refers to the issue of choosing the correct neighborhood measures. The neighborhood dimensions we used are included based on the interest being investigated and availability of data (see Leventhal and Brooks-Gunn, 2000; Minh et al., 2017), Finally, the endogeneity problem, which implies that neighborhood residence is not random but rather families choose to live in a neighborhood. For example, one scenario relevant to the present study could be a mother in anticipation of her pregnancy or early in pregnancy decides to move to an area close to a health clinic or to relatives/grandparents to facilitate her pregnancy and delivery, in particular to help raise children and ease the burden of motherhood. Another possibility would be a mother choosing to move to an area with people from the same ethnic background in order to derive support. It is also possible that a family on social benefits may live in the area where government houses are allocated. Further, Leventhal and Brooks-Gunn (2000) argued that a mother who resides in a poor neighborhood may do so to reduce her commuting time to spend more time with her children or because the rents are cheaper and the additional funds can be used for other activities for her children. In all these examples, the neighborhood of residence is an endogenous choice (the reason is unobserved by the researcher); without additional information, it is impossible to derive which scenario is more accurate. Moreover, the literature suggests that it is impossible to accurately estimate neighborhood effects in the presence of low birth weight because it is not known how much variation is attributable to individual versus neighborhood characteristics (see Leventhal and Brooks-Gunn, 2000).

While there have been many discussions on the potential associations between disadvantaged neighborhood, low birth weight, and problem behavior, limited studies have investigated all these three factors simultaneously to uncover empirically the pathways that yields these relationships. In addition, as several reviews on this topic have pointed out, the extant literature is often plagued by some key methodological issues that limit the validity of these studies. Earlier on, Leventhal and Brooks-Gunn (2000), for example, found that the available research findings are too scant to draw potential conclusions on pathways of neighborhood effects. Sellstrom and Bremberg (2006) concluded that the understanding of the causal path from the neighborhood context to birth and health outcomes is still limited. Recently, Minh et al. (2017) in a scoping review of 42 studies of neighborhood effects on developmental health for children aged 0-6 years old, concluded that the available research findings are incomplete to draw potential conclusions on causal pathways (how, for whom, and where) attributed to neighborhood effects.

The key problems, therefore, addressed by this study are two-fold. First, as mentioned above, previous studies suffer from the fundamental problem of not accounting for and separating out inherent influential factors related to residing in place ("endogeneity") in relation to health outcomes. The current study addresses this issue. Second, some studies have shown the outcomes at birth have a longer-lasting effect on developmental health, including problem behavior. By linking neighborhood, birth weight, and problem behavior, we describe the interrelationships amongst these three variables, and quantify their impact.

\section{Methodology}

\subsection{Conceptual framework}

Durlauf (2004) has suggested the mechanisms through which a neighborhood may affect individual behavior. First, an individual's behavior may reflect the average or aggregate behavior of the neighborhood (i.e., endogenous effects), and second, an individual's behavior may reflect the average background characteristics of the neighborhood (i.e., contextual effects). Extrapolating these to problem behavior, an endogenous effect is said to occur if a child's behavior is influenced by the problem behavior of other children in the neighborhood. A contextual effect is said to occur if the problem behavior is influenced by the socioeconomic composition of the neighborhood. Similarly, there is an endogenous effect on birth weight if individual birth weight depends on the average birth weight in the neighborhood, and there is a contextual effect if birth weight depends on the socioeconomic composition of the neighborhood. The relevance of this distinction is that only endogenous effects generate a social multiplier: An individual's behavior is not only influenced directly but also is influenced through the 'group' behavior involving other individuals in the neighborhood. Manski (1993) has identified this explanation as correlated effects, which means that individuals residing in the same neighborhood exhibit similar behavior because they share similar unobserved individual characteristics. For example, children in low-income and minority neighborhoods are more likely to be exposed to some adverse childhood experiences, such as witnessing discrimination or violence.

In the conceptual model, Fig. 1, we display the mechanisms we investigate. We assume that living in a disadvantaged neighborhood (Dn) has both a direct effect (through neighborhood structure/contextual effect) and an indirect effect, running through birth weight (Bw), on problem behavior $(\mathrm{Pb})$. Common unobserved factors that influence the choice residential neighborhood, in turn, may also affect both birth weight and problem behavior. One complexity these hypothetical relationships present is that the effect of birth weight on problem behavior

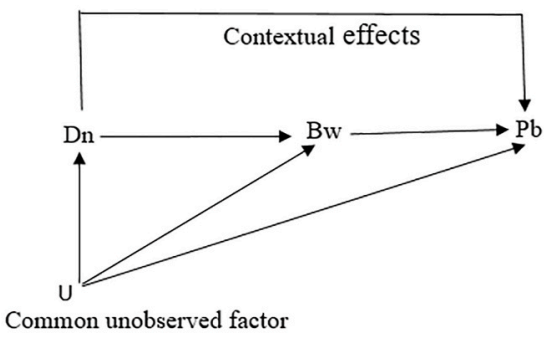

Fig. 1. Conceptual Modeling Framework. Note. Dn = Disadvantaged neighborhood, $\mathrm{Bw}=$ Birth weight, $\mathrm{Pb}=$ Problem behavior). 
is complicated by unobserved factors (endogenous factors) that affect both.

\subsection{Statistical model}

We seek to find the impact of both low birth weight and living in a disadvantaged neighborhood on the problem behavior in pre-school children. The main issue with analyzing these variables is that both the birth weight and the neighborhood choice (of the mother) may depend on (un)observed maternal characteristics that also influence problem behavior. Ignoring such endogeneity may lead to biased inference. In our model, we account for correlated effects, endogenous choice of location of residence, and contextual neighborhood effects through correlated errors.

To this end, we estimate a three equation system: (1) problem behavior, which may depend on both birth weight and disadvantaged neighborhood; (2) birth weight of a child, which may depend (among other control variables), on living in a disadvantaged neighborhood and (3) living in a disadvantaged neighborhood.

$$
\begin{aligned}
& Y_{i 2}{ }^{*}=\alpha_{1}+\gamma_{2} X_{i 0}+\beta_{2} X_{i 1}+\theta_{2} Z_{i}+\delta_{2} Y_{i 1}+\varepsilon_{i 2} \\
& Y_{i 1}=\alpha_{2}+\gamma_{1} X_{i 0}+\beta_{1} X_{i 1}+\theta_{l} Z_{i}+\varepsilon_{i 1} \\
& Z_{i}^{*}=\alpha_{z}+\gamma_{z} X_{i 0}+\varepsilon_{i z}
\end{aligned}
$$

The first and third equation are (standard) probit equations, which imply that we observe, living in a disadvantaged neighborhood, $Z_{i}=1$ if $Z \mathrm{i}^{*}>0$, and $Z_{i}=0$ otherwise and we observe, problem behavior, $Y_{i 2}=1$ if $Y_{i 2} *>0$, and $Y_{i 2}=0$ otherwise. The second equation is a standard linear equation for birth weight (for continuous variable). The main parameters of interest are the $\theta i$ 's, the effects of disadvantaged neighborhood, and $\delta_{2}$, the birth weight effect on problem behavior of children.

An important difference with standard (equation by equation) inference is that we allow for correlated errors, $\varepsilon=\left(\varepsilon_{\mathcal{Z}}, \varepsilon_{1}, \varepsilon_{2}\right)^{\prime} \approx N(0$, $\left.\sum\right)$.

$$
\text { and }
$$

$\sum=\left[\begin{array}{ccc}1 & \sigma \mathrm{z} 1 & \sigma \mathrm{z} 2 \\ \sigma \mathrm{z} 1 & \sigma 1 & \sigma 12 \\ \sigma \mathrm{z} 2 & \sigma 12 & 1\end{array}\right]$

with $\sigma_{12}=\rho_{12}, \sigma_{\mathrm{z} 1}=\rho_{\mathrm{z} 1}, \sigma_{\mathrm{z} 2}=\rho_{\mathrm{z} 2}$, where the $\rho^{\prime}$ s measure the correlation between the error terms (i.e., reflect the correlated effects).

\section{Data and sampling}

The data used for this study are obtained from Amsterdam Born Children and their Development (ABCD) cohort study (www.abcdstudie.nl). The study design and data collection procedure are explained elsewhere (Harskamp van Ginkel et al., 2015; Loomans et al., 2011), and we only summarize them here. Between January 2003 and March 2004, 12,373 pregnant women representing 99\% of the target population were visited for their first prenatal obstetric care. The target population was all the women who were pregnant and living in Amsterdam. Different sets of questionnaires covering a wide range of information were collected from mothers at different stages. Questionnaires were sent to their home address with return envelope and instructions. Out of 12,373, 8266 (67\%) mothers filled the pregnancy questionnaire at their 16 weeks of gestation and returned them. At the final stage, at age five, 6161 mothers were approached for a follow-up survey (twins were excluded), and among them, 4488 (73\%) mothers filled the child questionnaire.

For the purpose of this study, we merged two files to gather information from two rounds (pregnancy, and child questionnaire) and a neighborhood data file using four digits postal codes. Neighborhood data are available at the Central Bureau of Statistics (CBS) in the Netherlands (www.cbsinuwbuurt.nl/), Statistics Netherlands. CBS collects a range of personal information including citizenship, address, demographic, migration, social and economic indicators. At the beginning of each calendar year, Statistics Netherlands collects a selection of data for every registered person. In addition to this collection, when a person undergoes a demographic event, it is also updated in the register, and Statistics Netherlands is informed without delay by means of an electronic message. These data are the building blocks for the Dutch population statistics. These population register data are also used to construct sampling frames for surveys that are carried out by Statistics Netherlands. The neighborhood data are all based on administrative data for all officially registered individuals in a neighborhood. The administrative data from Statistics Netherlands are very accurate as registration is mandatory in the Netherlands. The sampling flows for the ABCD data are given in Fig. 2.

To address the potential problems with missing cases, we compared the results from a list-wise deletion analyses with multiple imputation (assuming missing at random). We, therefore, have used two sets of data for our analysis-a version with list-wise deletion cases with no missing observations on any included variable $(N=4210)$ and a version with values imputed in Stata software version 13 (StataCorp, 2001) using multivariate imputation chained equations (MICE; 20 iterations, $N=$ 4488) (for details about chained equations: Azur et al., 2011; White et al., 2011).The variables that are included in the imputation are: maternal work status during pregnancy, maternal education during pregnancy and at age 5 years of their child, birth weight of the child, household financial situation, smoking in the house and maternal depression during child's age at 5 years, disadvantaged neighborhood, problem behavior status, gestational age at birth (preterm birth), biological mother, and maternal anxiety during pregnancy. A linear regression imputation method is used for continuous variables and a logistic regression imputation method is used for binary variables. The degree of missing cases is reported in Table 1.

We also tested extensions of our model that take maternal health (and its possible endogeneity) explicitly into account, including separate, but possibly correlated, equations for maternal anxiety and maternal BMI. The results are reported in the results section and in the online supplements (Table S1).

\subsection{Construction of the relevant indicators}

\subsubsection{Problem behavior}

Children's problem behavior is reported in the child questionnaire by their mothers using the Strengths and Difficulties Questionnaire (SDQ). The questionnaire consists of 25 items, which are divided into five subscales: emotional symptoms, conduct problems, hyperactivity/inattention problems, peer relationship problems, and prosocial behavior Goodman (1997). Each item scores on a 3-point scale ( $0=$ 'not true,' $1=$ 'somewhat true,' and $2=$ 'certainly true'). A total SDQ score is calculated by aggregating the scores for the first four subscales of SDQ symptoms. The above 3-point scale of subscales of prosocial behaviors are coded differently than the subscales of other four behavioral problems, and therefore, the subscales of prosocial behaviors are not included in the calculation of our total SDQ score (in deriving problem behavior measure); for details, see Goodman (1997). The total score consists of a range of values from 0 to 33 in our parent rating sample. Following the cutoff points developed for the Netherlands, we used the following cutoff points to create a three-category variable of total Strengths and Difficulties (TSDQ) score: 1 normal $=0-10,2$ borderline $/$ moderate $=11-13$, and 3 abnormal $=14$ plus (Muris et al., 2003). Finally, we created a dummy of normal ( 0 ) versus moderate/abnormal (1).

\subsubsection{Disadvantaged neighborhood}

Following previous studies, six neighborhood factors were identified from CBS along with four-digit postal codes (Turney and Harknett, 2010). The variables are: percent not participating on the labor market, 
Pregnancy file (F1), n=8266 children (mothers were completed questionnaire)

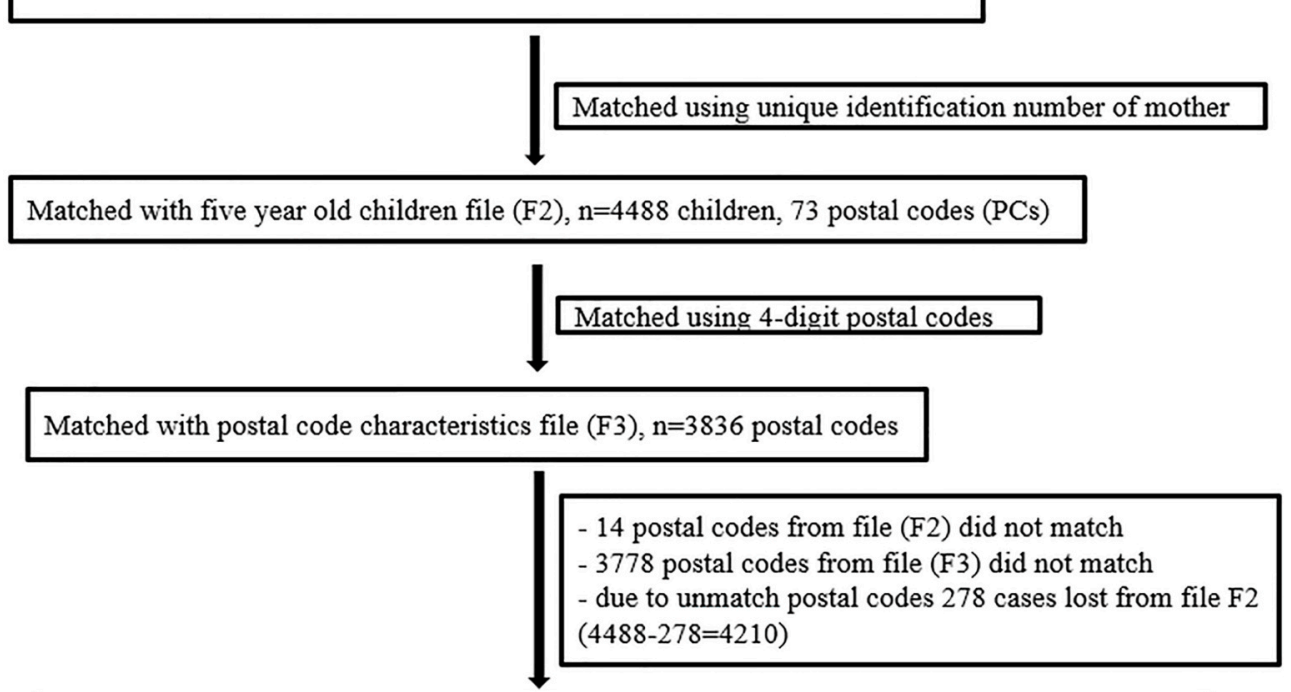

Final sample children file (F4), $n=4210$ children, postal codes $=59$, average 71 children per $P C$

Fig. 2. Sampling flow.

percent low income, percent on pension, number on social benefits, number on disability-benefits, and number on unemployment benefits. To account for social cohesion in the neighborhood (Jackson et al., 2019), we also added three criminality measurements to the disadvantage neighborhood indicator: number of burglaries from houses per 1000 inhabitants; number of vandalism and public order offences per 1000 inhabitants and number of violence (including sexual violence) per 1000 inhabitants. We created an index by adding up the standardized values of all indicators (z-score). The higher the score, the more disadvantaged the area. Based on these scores, we define a neighborhood disadvantaged when the neighborhood score is in the highest $20 \%$ of the scores.

\subsubsection{DASS-21 score}

Generalized anxiety during pregnancy was assessed using the Dutch version of the State-Trait Anxiety Inventory (STAI) around the 16th week of gestation (Spielberger et al., 1970). The 20 items regarding state anxiety (transient or temporarily experienced anxiety) were included in the questionnaire with each item scored on a 4-point scale; a higher score represents a higher level of experienced anxiety. We also include a dummy variable of maternal anxiety and stress over the first five years of their children's lives (DASS-21 score $\geq 1=1$, otherwise $=0$ ); this variable was assessed by the Depressive Anxiety and Stress Scale 21 (DASS-21) (see Lovibond and Lovibond, 1995).

\section{Results}

\subsection{Sample statistics}

Table 1 reports the sample characteristics. About $11 \%$ of all sampled mothers reported presence (moderate or abnormal) of problem behavior in their children. Sixty-two percent of families indicated that they had some savings and about one-fourth (26\%) of sample mothers reported depressive symptoms sometime during the first five years of their children's lives.

The mean age of the mothers was 31.6 years, with a standard deviation of 4.7. About half (46.3\%) of the mothers had nine to 12 years of schooling; Sixteen percent of the mothers had less than six years of schooling. Two-thirds (66\%) of the mothers were Dutch natives. $22.5 \%$ of all mothers were classified as overweight (BMI > 24.9), while $4.2 \%$ were classified as underweight $(<18.5)$. The prevalence of antenatal anxiety was severe (STAI score $\geq 51$ ) among $10.7 \%$ of the mothers and was very low (STAI score $<36$ ) for about $50 \%$ of the mothers during their pregnancy. Less than $10 \%$ of the mothers were smoking during pregnancy. Eighty percent of all the mothers were employed. Five percent of all children were born before 37 weeks of gestation, which is defined as preterm birth. The average birth weight was $3467 \mathrm{~g}$ with a standard deviation of $542 \mathrm{~g}$.

About $19 \%$ of sampled mothers were located in a disadvantaged area (see our definition of a disadvantaged neighborhood above). A small portion of the mothers, $12 \%$, moved between birth and the interview, which is reflected in the mismatch between the mothers' postal codes in the pregnancy questionnaire and the child questionnaire.

\subsection{Estimation results}

We exploited the conditional mixed model of the cmp command in Stata, which is a general framework to estimate models with various link functions (Roodman, 2011). Table 2 reports the coefficient estimates of problem behavior reported by their parents (equation (1)) (Panel A) in 5-6 year old children, birth weight (equation (2)) (Panel B), and residence in disadvantaged neighborhood (equation (3)) (Panel C). We estimated two models: an uncorrelated (model 1) and a correlated (model 2; benchmark/correlated model).

Our main interest was the impacts of birth weight and living in a disadvantaged neighborhood on the probability of problem behavior, which are shown in Panel A of Table 2. Living in a disadvantaged neighborhood increases the probability of problem behavior, and accounting for endogeneity of neighborhood choice (i.e., correlated errors) triples the estimated impact (marginal effects $11 \%$ after adjusting correlations instead of $3 \%$ non-adjusted). Similarly, the birth weight's effect is significantly negatively associated in the benchmark model. As birth weight increases, it decreases the likelihood of problem behavior in 5-6 year-old children. The coefficients of the other factors have the expected signs.

Panel B of Table 2 presents the estimated coefficients of the birth weight equation. Living in a disadvantaged neighborhood is significantly associated with a reduction in birth weight in the benchmark model (44\%). Nevertheless, ignoring endogeneity (model 1) would 
Table 1

Sample characteristics, $\mathrm{N}=4488$.

\begin{tabular}{|c|c|c|c|}
\hline Characteristics & $N$ & $\begin{array}{l}\text { Missing } \\
\text { observations }\end{array}$ & $\begin{array}{l}\text { Valid } \\
\text { percentage }\end{array}$ \\
\hline \multicolumn{4}{|c|}{ Child questionnaire (child's age 5-6 year old): } \\
\hline Total problem behavior SDQ score & 4454 & 34 & \\
\hline Normal & & & $89.38(3981)$ \\
\hline Moderate/abnormal, score $\geq 11$ & & & $10.62(473)$ \\
\hline Family financial status & 4402 & 86 & \\
\hline Have no sufficient savings & & & $38.14(1679)$ \\
\hline Have some/sufficient savings & & & $61.86(2723)$ \\
\hline Maternal levels of education & 4447 & 41 & \\
\hline Below university levels & & & $34.07(1515)$ \\
\hline University levels & & & $65.93(2932)$ \\
\hline $\begin{array}{l}\text { Maternal stress during } 5 \text { years old } \\
\text { of child DASS-21 }\end{array}$ & 4016 & 472 & \\
\hline Score 0 & & & $74.08(2975)$ \\
\hline Score $\geq 1$ & & & $25.92(1041)$ \\
\hline $\begin{array}{l}\text { Smokers at home (child' age 5-6 } \\
\text { year old), Yes }\end{array}$ & 4032 & 456 & $8.53(344)$ \\
\hline \multicolumn{4}{|l|}{ Pregnancy questionnaire: } \\
\hline Mother's age at birth Mean $(S D)$ & 4488 & 0 & $31.63(4.70)$ \\
\hline $\begin{array}{l}\text { Schooling years of mother during } \\
\text { pregnancy }\end{array}$ & 4466 & 22 & \\
\hline$\leq 5$ years schooling & & & $15.63(698)$ \\
\hline $6-8$ years schooling & & & $19.19(857)$ \\
\hline 9-12 years schooling & & & $46.33(2069)$ \\
\hline $13+$ & & & $18.85(842)$ \\
\hline Ethnicity: & 4488 & 0 & \\
\hline Dutch & & & $65.31(2931)$ \\
\hline Surinamese & & & $4.99(210)$ \\
\hline Moroccan/Turkish/Other & & & $11.40(480)$ \\
\hline Other, non-western country & & & $5.23(220)$ \\
\hline Other, western country & & & $12.21(514)$ \\
\hline $\begin{array}{l}\text { Pre-pregnancy maternal body } \\
\text { mass index }\end{array}$ & 4488 & 0 & \\
\hline $\begin{array}{l}\text { Normal weight (BMI } \geq 18.5 \\
\quad \&<24.9 \text { ) }\end{array}$ & & & $73.17(3284)$ \\
\hline Obesity/overweight (BMI $\geq 24.9$ ) & & & $22.59(1014)$ \\
\hline Underweight $(\mathrm{BMI}<18.5)$ & & & $4.23(190)$ \\
\hline Antenatal maternal anxiety (STAI) & 4439 & 49 & \\
\hline Very low & & & $49.36(2191)$ \\
\hline Medium & & & $39.92(1772)$ \\
\hline Severe & & & $10.72(476)$ \\
\hline $\begin{array}{l}\text { During pregnancy maternal } \\
\text { smoking, Yes }\end{array}$ & 4488 & 0 & $8.78(394)$ \\
\hline $\begin{array}{l}\text { Mother works (during pregnancy) } \\
\text { Yes }\end{array}$ & 4455 & 33 & 79.66 (3549) \\
\hline Non-biological mother Yes & 4472 & 16 & $2.84(127)$ \\
\hline Gender of child Boy & 4488 & 0 & $50.47(2265)$ \\
\hline Preterm birth $<37$ weeks & 4482 & 6 & $4.80(215)$ \\
\hline Birth weight (grams) Mean ( $S D$ ) & 4465 & 23 & $3467(542)$ \\
\hline Neighborhood levels: & 4210 & 278 & \\
\hline Advantaged neighborhood & & & $80.52(3390)$ \\
\hline Disadvantaged neighborhood & & & $19.48(820)$ \\
\hline Residential stability $^{\text {a }}$ & 4210 & 278 & \\
\hline Move over time & & & $12.38(521)$ \\
\hline Do not move over time & & & $87.62(3689)$ \\
\hline
\end{tabular}

Note. ${ }^{\text {a }}$ Postal codes vary between pregnancy and at five-year-old questionnaire.

render the neighborhood effect small (8\%). The coefficients of all the other included variables have the expected sign, revealing that maternal life style and maternal pregnancy characteristics are important predictors of birth weight.

Panel C of Table 2 presents the estimated coefficient of the probability of living in a disadvantaged neighborhood. We found that native Dutch women are less likely to live in a disadvantaged neighborhood. The probability of living in a disadvantaged neighborhood decreases with each higher level of maternal education. The coefficients of all the included variables have the expected signs.

The results show that the effect of disadvantaged neighborhood and birth weight on problem behavior decreases slightly in the more extended models, as does the effect of disadvantaged neighborhood on birth weight (Table S1).
To address some missing observations of included variables, we also estimated the model using multiple imputations of these missing data (using cmdok in Stata). The results are given in Tables S2-S3 and hardly differ from the model estimates using case-wise deletion. We further investigated whether the results vary by subscale of problem behavior. We found similar estimates for different subscale of problem behavior (e. g., conduct problem: prevalence $=12.4 \%$, ADHD problem: prevalence $=41 \%$ ); see Table S4.

\subsection{Correlated error terms}

The correlations amongst the error terms, reported in Table 3, reveal that the problem behavior and disadvantaged neighborhood equations are negatively correlated $\left(\rho_{13}\right)$. This finding suggests that important, but unobserved, individual factors exist that both increased the chances of living in a disadvantaged neighborhood and reduced problem behavior. The correlation between the problem behavior and the birth weight equations $\left(\rho_{12}\right)$ is positive but not statistically significant. The large positive correlation between the birth weight and disadvantaged neighborhood equations $\left(\rho_{23}\right)$ confirms that both outcomes are strongly related and that unobserved individual factors increased the probability of living in a disadvantaged area and simultaneously increased birth weight.

\section{Discussion}

A key methodological challenge to overcome in studies demonstrating neighborhood effects centers on the concept of correlated 'causes' or endogeneity. This issue implies for our application that factors that influence neighborhood choice also influence simultaneously birth weight and problem behavior. If not all relevant factors are observed (which is usually the case) then the neighborhood choice, birth weight, and problem behavior are correlated through these unobserved factors, and ignoring these factors will lead to biased inference on neighborhood contextual effects in traditional regression analysis.

Using a model that accounts for endogeneity of neighborhood choice and birth weight, we have analyzed behavioral problems in pre-school children, birth weight, and neighborhood status simultaneously (see Table 2, model 2). The nature of the model addressed the endogenous neighborhood choice in the analysis. The data used are from the ABCD cohort study on children for whom a complete prospective record of birth outcome, total SDQ, maternal lifestyle and anxiety characteristics, and socio-demographic variables are available. Neighborhood data are merged with the ABCD data file.

It is evident from our analysis that the neighborhood disadvantage increased the risk of low birth weight and problem behavior. It is already known that the risk of negative outcomes is lower in socially advantaged families. Our main contribution is that by linking neighborhood, birth weight, and problem behavior, we quantified the inter-relationships amongst these three variables. We find a significant and large effect of living in a disadvantaged neighborhood, an $11 \%$ increase in the probability of problem behavior, compared to conventional estimates of a $3 \%$ increase (marginal effects; see Table 2, model 2 vs. model 1). As discussed by Leventhal and Brooks-Gunn (2000), this finding supports the hypothesis of underestimated neighborhood effects. Our analysis also confirms the association between area deprivation and problem behavior in children in the Netherlands (Reijneveld et al., 2010; Spijkers et al., 2011) and corrected methodological flaws evident in previous studies that may have led to underestimated effect sizes (Dietz, 2002; Durlauf, 2004; Grafova et al., 2014; Leventhal and Brooks-Gunn, 2000; Pickett and Pearl, 2001; Sellstorm and Bremberg, 2006).

Methodological problems frequently plague neighborhood effects research, for example, the individual level omitted variables may result in non-exchangeability of individuals across neighborhoods, even when measured individual level covariates are included; see Oakes (2004). This issue is referred as the omnipresent "residual confounding" 
Table 2

Parent reported problem behavior and associated parameter estimates based on uncorrelated (model 1) and correlated (model 2; benchmark), N = 4210.

\begin{tabular}{|c|c|c|}
\hline & $\begin{array}{l}\text { Coefficients (model } 1 \text { ) } \\
(\rho 12, \rho 13, \rho 23=0)\end{array}$ & $\begin{array}{l}\text { Coefficients (model 2) } \\
(\rho 12, \rho 13, \rho 23<>0)\end{array}$ \\
\hline \multicolumn{3}{|l|}{ Panel A (Equation (1)) } \\
\hline Parent reported problem behavior in children (probit model) & $N=3662$ & \\
\hline Birth weight of child $(\mathrm{kg})$, continuous variable & $-0.107(-0.214,0.001)^{*}$ & $-0.277(-0.48,-0.072)^{* *}$ \\
\hline Residence is in disadvantage neighborhood & $0.209(0.067,0.352)^{* * *}$ & $0.654(0.274,1.035)^{* * *}$ \\
\hline Gender of child Male & $0.307(0.187,0.426) * * *$ & $0.321(0.202,0.440)^{* * *}$ \\
\hline Family financial status Has some/sufficient savings & $-0.342(-0.466,-0.218)^{* * *}$ & $-0.306(-0.430,-0.182)^{* * *}$ \\
\hline Mother's level of education: University level & $-0.227-0.357,-0.986)^{* * *}$ & $-0.155(-0.290 .-0.021)^{* *}$ \\
\hline Maternal anxiety and stress DASS-21, Score $\geq 1$ & $0.427(0.303,0.552)^{* * *}$ & $0.414(0.292,0.536)^{* * *}$ \\
\hline Mother is not biological & $0.364(0.070,0.659)^{* *}$ & $0.98(0.008,0.588)^{* *}$ \\
\hline Smokers at home & $0.207(0.021,0.392)^{* *}$ & $0.188(0.006,0.369)^{* *}$ \\
\hline Panel B (Equation (2)) & $N=4112$ & \\
\hline \multicolumn{3}{|l|}{ Birth weight (linear regression) } \\
\hline Residence is in disadvantage neighborhood & $-0.082(-0.120,-0.043)^{* * *}$ & $-0.437(-0.524,-0.350)^{* * *}$ \\
\hline Gender of child Male & $0.134(0.105,0.163)^{* * *}$ & $0.135(0.106,0.164)^{* * *}$ \\
\hline Preterm birth $<37$ weeks & $-1.089(-1.158,-1.020)^{* * *}$ & $-1.074(-1.14,-1.005)^{* * *}$ \\
\hline Maternal age at birth (years), continuous & $0.006(0.003,0.009)^{* * *}$ & $0.004(0.001,0.007)^{* *}$ \\
\hline \multicolumn{3}{|l|}{ Maternal pre-pregnancy BMI } \\
\hline Obesity/overweight $\geq 24.5$ & $0.099(0.063,0.135)^{* * *}$ & $0.115(0.080,0.151)^{* * *}$ \\
\hline Underweight $<18.5$ & $-0.256(-0.330,-0.182)^{* * *}$ & $-0.249(-0.32,-0.176)^{* * *}$ \\
\hline Maternal smoking Yes & $-0.171(-0.223,-0.119)^{* * *}$ & $-0.161(-0.213,-0.109)^{* * *}$ \\
\hline \multicolumn{3}{|l|}{ Maternal pregnancy antenatal anxiety } \\
\hline Medium & $-0.064(-0.095,-0.033)^{* * *}$ & $-0.057(-0.088,-0.025)^{* * *}$ \\
\hline Severe & $-0.085(-0.136,-0.034)^{* * *}$ & $-0.071(-0.123,-0.019)^{* *}$ \\
\hline Maternal working status Yes & $-0.030(-0.069,0.008)$ & $-0.071(-0.110,-0.033)^{* * *}$ \\
\hline Panel C (Equation (3)) & $N=4190$ & \\
\hline \multicolumn{3}{|l|}{ Disadvantage Neighborhood (probit model) } \\
\hline Ethnicity Surinamese & $1.155(0.966,1.344)^{* * *}$ & $1.203(1.021,1.384)^{* * *}$ \\
\hline Morrocan/Turkish/Other & $0.725(0.582,0.868)^{* * *}$ & $0.725(0.589,0.860)^{* * *}$ \\
\hline Other Non-western & $0.598(0.408,0.787)^{* * *}$ & $0.651(0.474,0.827)^{* * *}$ \\
\hline Other Western & $0.088(-0.060,0.235)$ & $0.120(-0.018,0.259)$ \\
\hline \multicolumn{3}{|l|}{ Maternal schooling years during pregnancy } \\
\hline $6-8$ & $-0.183(-0.328,-0.038)^{* *}$ & $-0.152(-0.288,-0.017)^{* *}$ \\
\hline $9-12$ & $-0.446(-0.584,-0.307)^{* * *}$ & $-0.446(-0.596,-0.336)^{* * *}$ \\
\hline $13+$ & $-0.571(-0.742,-0.401)^{* * *}$ & $-0.587(-0.748,-0.425)^{* * *}$ \\
\hline Multi paras mother Parity $\geq 1$ & $0.063(-0.031,0.156)$ & $-0.055(-0.146,0.035)$ \\
\hline Variance in birth weight equation & $0.475(0.465,0.485)^{* * *}$ & $-0.493(0.480,0.508)^{* * *}$ \\
\hline
\end{tabular}

Note. Reference categories are: Panel A: Advantaged neighborhood, female child, family does not have sufficient savings, maternal levels of education below university level, DASS-21 score of 0, mother is the biological mother, no smokers at home. Panel B: Advantaged neighborhood, female child, not preterm birth, maternal prepregnancy BMI between 18.5 and 24.0, no maternal smoking during pregnancy, little antenatal anxiety, no work. Panel C: Dutch native, mother's schooling years below 6, no parity.

Model 1: The three equations are assumed independent (i.e., no correlated effects and estimated separately).

Model 2: Full model, allowing for correlation among the three error terms.

$\rho_{\mathrm{s}}$, are correlations, and subscript indicates equation number. Ninety-five percent confidence intervals $(C I s)$ are given within brackets. Significance at * $p=0.05,{ }^{*} p<$ $0.05, * * p \leq 0.001$.

problem in epidemiologic studies. Others (Joffe and Rosenbaum, 1999; Rubin, 1997) demonstrated that propensity score approach does not resolve the problems of omitted variables. Thus, our estimation method that controls for unobserved correlated factors may better account for the complex causal effects (Robins et al., 2000).

Accounting for endogeneity (that may arise due to unobserved

Table 3

Parent-reported problem behavior-benchmark model (model 2), estimated correlations of Idiosyncratic error terms associated with each equation-problem behavior (Eq (1)), birth weight (Eq (2)) and disadvantaged neighborhood (Eq (3)).

\begin{tabular}{llll}
\hline & $\begin{array}{l}\text { Problem } \\
\text { behavior }\end{array}$ & Birth weight & $\begin{array}{l}\text { Disadvantaged } \\
\text { neighborhood }\end{array}$ \\
\hline $\begin{array}{l}\text { Problem behavior } \\
\text { Birth weight }\end{array}$ & 1 & & \\
& $\left(\rho_{12}\right)$ & 1 & \\
& $0.059(-0.067$, & & \\
Disadvantaged & $0.183)$ & & \\
$\quad$ neighborhood & $\left(\rho_{13}\right)$ & $\left(\rho_{23}\right)$ & 1 \\
& -0.279 & $0.449(0.356$, & \\
& $(-0.469$, & $0.533)^{* * *}$ & \\
\hline
\end{tabular}

Note. $\rho_{\mathrm{s}}$, are correlations, and subscript indicates equation number.

Significance at $* p=0.05,{ }^{* *} p<0.05,{ }^{* * *} p \leq 0.001$. factors that influence all three outcomes) in the analysis increases the estimated effect of living in a disadvantaged neighborhood on birth weight and on problem behavior. Failing to include potentially important covariates (omitted variables problem) in the model might lead to an unobserved heterogeneity (unobserved variability) in the response variable. The result sheds light on the findings of Kelly et al. (2001) and others (see Laucht et al., 2001; Shah et al., 2013; Tully et al., 2004) that birth outcome and social environment exert potentially interactive effects on behavior in children. This finding is also in line with other findings in the literature (Lau and Morse, 2003; Miles and Holditch-Davis, 1997) that parents of preterm-born children often experience an increased level of stress, which could influence parental behavior and parent-child interactions, exacerbated by living in disadvantaged neighborhood. The relatively strong association of the neighborhood context with problem behavior may be explained by norms and collective efficacy in these neighborhoods that shape child behavior (Leventhal and Brooks-Gunn, 2000; Minh et al., 2017).

In our benchmark analysis (Table 2, model 2), we find evidence of a larger effect size of problem behavior in boys, which may be a sign of externalizing problems. Jackson and Vaughn (2018) found that the predictive probability of externalizing behavior among boys increased in presence of three or more maternal medical risks during pregnancy. Children from families with enough financial savings and mothers with 
higher levels of education are less likely to exhibit problem behavior, and this finding is in line with others (see Fan et al., 2013).

While there is some concern regarding selective reporting of problem behavior by parents, our conclusions remained the same when using teacher-reported problem behavior instead (Tables S5-S6). de Laat et al. (2015), using this same cohort of children (i.e., ABCD cohort), found no difference in problem behavior reported by parents or teachers. Yet, they did not compare their results by residential disadvantaged neighborhood. Agyemang et al. (2009) analyzed birth outcomes of this same cohort and estimated the neighborhood level income and unemployment/social benefits on pregnancy outcomes. But, they did not account for simultaneity of the events and neighborhood disadvantage (collective efficacy in birth outcomes) or quantifying such effects.

Correlated effects arise because individuals are not randomly distributed across neighborhoods; individuals sort themselves into neighborhoods on the basis of personal and family background characteristics (Grafova et al., 2014; Reardon et al., 2015), and these characteristics, in turn, could influence both birth weight and problem behavior.

\section{Limitations}

Due to failure of matching samples across different files (i.e., pregnancy, child, and neighborhood), we lost some cases. Thus, attrition is a limitation in our study. We checked our sample for residential stability from pregnancy to five years post-delivery. Yet, we did not include this variable in our final model. We also have some missing observations for a few explanatory variables included in the model. We have also checked the sensitivity of dropping these missing families. This issue only marginally changed the coefficients of the neighborhood and birth weight effects on problem behavior (results are available upon request). Further, we have performed analyses to compare case-wise deletion with multiple imputations to deal with missing observations of some variables. Although we found some variation in the coefficients of the separate models (ignoring endogeneity), no significant differences were observed in the coefficients in our final model (see correlated model, column 2, in Table 2 and Table S2). Of course, neighborhood choice is neither fully at random nor completely unrestricted. Some people post their choice for subsidized housing and wait until such a house becomes available, while others directly enter subsidized housing. In principle, this variance may violate our modeling concept of neighborhood as choice variable. Yet, even with allocated housing, most of the neighborhoods people are living in are also related to other characteristics of the individuals, (e.g., income level) and are, therefore, endogenous. Although we account for endogeneity through correlated errors, we cannot claim to obtain causal effects, as our model relies on the functional restriction of multivariate normality. Nonetheless, we believe our model provides a closer estimate of the true causal impact than results from previous models of birth weight and neighborhood influence on problem behavior that completely ignore this endogeneity.

\section{Conclusions}

Our benchmark finding, a significant (11\% increase) neighborhood effect on problem behavior, highlights the importance of neighborhood level analysis on determinants of problem behavior in pre-school children. This study has demonstrated an improved approach (methodological approach) to the analysis of neighborhood effects and has shown associations between individual factors and an intervening variable, birth weight, on child behavioral problems. Community-based interventions that target families and their social contexts are very important, as problem behavior in children are observed in neighborhood contexts.

\section{Contributors}

URS has contributed in conceptualization, model specification, drafting and editing the manuscript with interpretation of the results. URS also has contributed in data management/curation, formal statistical analysis and data visualization. GB has contributed in conceptualization, model specification, formal statistical analysis, drafting and editing the manuscript with interpretation of the results. NM has contributed in conceptualization and editing the manuscript with interpretation of the results. TV has contributed in designing the survey, data collection, and editing the manuscript with interpretation of the results.

\section{Exclusive licence}

The Corresponding Author has the right to grant on behalf of all authors and does grant on behalf of all authors, an exclusive licence (or non-exclusive for government employees) on a worldwide basis to the BMJ Publishing Group Ltd and its Licensees to permit this article (if accepted) to be published in JECH editions and any other BMJPGL products.

\section{Funding}

The author (s) received no specific funding for this study.

Compliance with ethical standards.

\section{Ethical standards}

Approval for the ABCD study was obtained from the Central Committee on Research involving Human Subjects in the Netherlands, the Medical Ethical Committees of the participating hospitals, and from the Registration Committee of the Municipality of Amsterdam. Written informed consent was obtained from all participants. This ABCD study was supported by the Netherlands Organization for Health Research and Development (ZonMw).

\section{Declaration of competing interest}

The authors declare that there are no conflicts of interest.

\section{Acknowledgements}

The authors thank Amsterdam Medical centre for providing data for this research and Dr. David Roodman for his support on replying some queries on using conditional mixed model in Stata.

\section{Appendix A. Supplementary data}

Supplementary data to this article can be found online at https://doi. org/10.1016/j.socscimed.2020.113400.

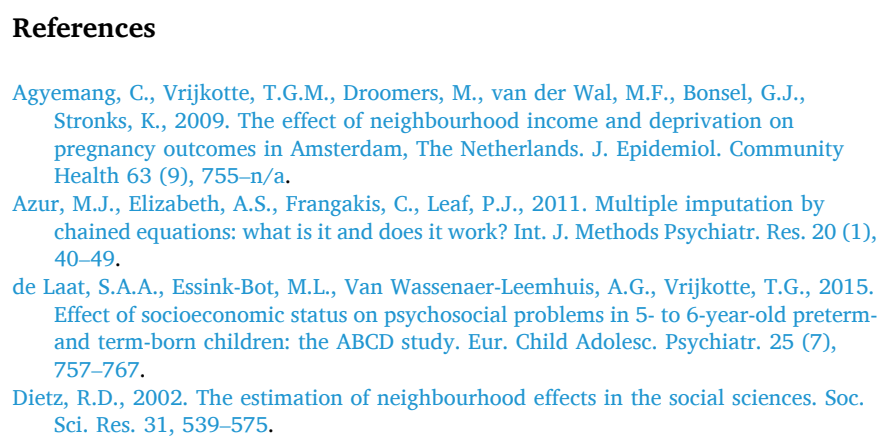


Durlauf, S.N., 2004. Neighbourhood effects. In: Henderson, J.V., Thesse, J.F. (Eds.), Handbook of Regional and Urban Economics, vol. 4. North-Holland Amsterdam, pp. 2173-2242.

Fan, R.G., Portuguez, M.W., Nunes, M.L., 2013. Cognition, behavior and social competence of preterm low birth weight children at school age. Clinics 68 (7), 915-921.

Gavin, A.R., Nurius, P., Logan-Greene, P., 2012. Mediators of adverse birth outcomes among socially disadvantaged women. J. Womens Health (Larchmt) 21 (6), 634-642.

Goodman, R., 1997. The Strengths and Difficulties questionnaire: a research note. JCPP (J. Child Psychol. Psychiatry) 38 (5), 581-586.

Grafova, I.B., Freedman, V.A., Lurie, N., Kumar, R., Rogowski, J., 2014. The differencein-difference method: assesssing the selection bias in the effects of neighborhood environment on health. Econ. Hum. Biol. 13, 20-33.

Harskamp-van Ginkel, M.W., London, S.J., Magnus, M.C., Gademan, M.G., Vrijkotte, T. G., 2015. A study on mediation by offspring BMI in the association between maternal obesity and child respiratory outcomes in the Amsterdam born and their development study cohort. PloS One 10 (10), 1-13.

Hille, E.T., den Ouden, A.L., Saigal, S., Wolke, D., Lambert, M., Whitaker, A., et al., 2001. Behavioural problems in children who weigh $1000 \mathrm{~g}$ or less at birth in four countries. Lancet 357, 1641-1643.

Hornman, J., de Winter, A.F., Kerstjens, J.M., Bos, A.F., Reijneveld, S.A., 2016. Emotional and behavioral problems of preterm and full term children at school entry. Pediatrics 137 (5), 1-9.

Jackson, D.B., Beaver, K.M., 2015. Sibling differences in low birth weight, dopaminergic, polimorphisms and ADHD symptomatology: evidence of GxE. J. Psychiatr. Res. 226, 467-473.

Jackson, D.B., Vaughn, M.G., 2018. Maternal medical risks during pregnancy and childhood externalizing behavior. Soc. Sci. Med. 207, 19-24.

Jackson, D.B., Johnson, K.R., Vaughn, M.G., Marissa, E., Hinton, M.E., 2019. The role of neighborhoods in household food insufficiency: considering interactions between physical disorder, low social capital, violence and perceptions of danger. Soc. Sci. Med. 221, 58-67.

Joffe, M.M., Rosenbaum, P.R., 1999. Invited commentary: propensity scores. Am. J. Epidemol. 150, 327-333.

Kelly, Y.J., Nazroo, J.Y., McMunn, A., Boreham, R., Marmot, M., 2001. Birth weight and behavioural problems in children: a modifiable effect? Int. J. Epidemiol. 30 (1), 88-94.

Lau, R., Morse, C.A., 2003. Stress experiences of parents with premature infants in a special care nursery. Stress Health 19, 69-78.

Laucht, M., Esser, G., Schmidt, M.H., 2001. Differential development of infants at risk for psychopathology: the moderating role of early maternal responsivity. Dev. Med. Child Neurol. 43 (5), 292-300.

Leventhal, T., Brooks-Gunn, J., 2000. The neighbourhoods they live in. Psychol. Bull. 126 (2), 309-337.

Loomans, E.M., vander Stelt, O., van Eijsden, M., Gemke, R.J.B.J., Vrijkotte, T.G., Vanden Bergh, B.R.H., 2011. Antenatal maternal anxiety is associated with problem behaviour at age five. Early Hum. Dev. 87 (8), 565-570.

Lovibond, S.H., Lovibond, P.F., 1995, second ed.. Manual for the Depression Anxiety Stress Scales. Psychology Foundation, Sydney.

Manski, C.F., 1993. Identification of endogenous social effects: the reflection problem. Rev. Econ. Stud. 60, 531-543.

Minh, A., Muhajarine, N., Janus, M., Brownell, M., Guhn, M., 2017. A review of neighborhood effects and early child development: how, where, and for whom, do neighborhoods matter. Health Place 46, 155-174.
Miles, M.S., Holditch-Davis, D., 1997. Parenting the prematurely born child: pathways of influence. Semin. Perinatol. 21, 254-266.

Muris, P., Meesters, C., van den Berg, F., 2003. The Strengths and Difficulties Questionnaire (SDQ): further evidence for its reliability and validity in a community sample of Dutch children and adolescents. Eur. Child Adolesc. Psychiatr. 12, 1-8.

Oakes, M.J., 2004. The (mis)estimation of neighborhood effects: causal inference for a practicable social epidemiology. Soc. Sci. Med. 58 (10), 1929-1952.

Pickett, K.E., Pearl, M., 2001. Multilevel analyses of neighbourhood, socioeconomic context and health outcomes: a critical review. J. Epidemiol. Community Health 55, $111-122$.

Reardon, S.F., Fox, L., Townsend, J., 2015. Neighborhood income composition by household race and income, 1990-2009. Ann. Am. Acad. Polit. Soc. Sci. 660 (1), 78-97.

Reijneveld, S.A., Veenstra, R., de Winter, A.F., Verhulst, F.C., Ormel, J., Meer, G., 2010. Area deprivation affects behavioral problems of young adolescents in mixed urban and rural areas: the TRAILS study. J. Adolesc. Health 46, 189-196.

Robins, J.M., Ángel, H.M., Babette, B., 2000. Marginal structural models and causal inference in epidemiology. Epidemiology 11, 550-560.

Robinson, M., Mattes, E., Oddy, W.H., de Klerk, N.H., Li, J., McLean, N.J., et al., 2009. Hypertensive diseases of pregnancy and the development of behavioral problems in childhood and adolescence: the Western Australian Pregnancy Cohort Study. J. Pediatr. 154 (2), 218-224.

Roodman, D., 2011. Fitting fully observed recursive mixed-process models with cmp. STATA J. 11, 2.

Rubin, D.B., 1997. Estimating causal effects from large data sets using propensity scores. Ann. Intern. Med. 127, 757-763.

Sameroff, A.J., Chandler, M.J., 1975. Reproductive Risk and the Continum of Caretaking Causality. In: Horowitz, F.D., Hetherington, M., Scarr-Salapatek, S., Siegel, G. (Eds.), Review of Child Development Research, vol. 4. Chicago: University of Chicago Press.1, pp. 187-244.

StataCorp.. Statistical Software: Release, 13.0, 2001. Stata Corporation, College Station, TX.

Sellstrom, E., Bremberg, S., 2006. The significance of neighbourhood context to child and adolescent health and wellbeing: a systematic review of multilevel studies. Scand. J. Publ. Health 34, 544-554.

Shah, P.E., Robbins, N., Coelho, R.B., Poehlmann, J., 2013. The paradox of prematurity: the behavioral vulnerability of late preterm infants and the cognitive susceptibility of every preterm infants at 36 months post-term. Infant Behav. Dev. 36 (1), 50-62.

Spielberger, C.D., Gorsuch, R., Lushene, R.E., Vagg, P.R. (Eds.), 1970. STAI Manual for the State Trait Anxiety Inventory. Consulting Psychologists Press, Palo Alto, CA.

Spijkers, W., Jansen, D., Reijneveld, S.A., 2011. The impact of area deprivation on parenting stress. Eur. J. Publ. Health 22 (6), 760-765.

Shum, D., Neulinger, K., O'Callaghan, M., Mohay, H., 2008. Attentional problems in children born very preterm or with extremely low birth weight at 7-9 years. Arch. Clin. Neuropsychol. 23, 103-112.

Tully, L., Arseneault, L., Caspi, A., Moffitt, T.E., 2004. Does maternal warmth moderate the effects of birth weight on twins' attention-deficit/hyperactivity disorder (ADHD) symptoms and low IQ? J. Consult. Clin. Psychol. 72 (2), 2018.

Turney, K., Harknett, K., 2010. Neighborhood disadvantage, residential stability, and perceptions of instrumental support among new mothers. J. Fam. Issues 31 (4), 499-524.

Wiles, N.J., Peters, T.J., Heron, J., Gunnell, D., Emond, A., Lewis, G., 2006. Fetal growth and childhood behavioral problems: results from the ALSPAC cohort. Am. J. Epidemiol. 163, 829-837.

White, I.R., Royston, P., Wood, A.M., 2011. Multiple imputation using chained equations: issues and guidance for practice. Stat. Med. 30, 377-399. 